\title{
Educational Problems and Improvement on Ulleungdo Islands in Korea
}

\author{
Jihoon Kim (corresponding author) \\ Gyeongbuk Women's Policy Development Institute \\ wildmet@naver.com
}

\author{
Hye Jung Lee \\ Institute of Educational Welfare Policy, Hanyang University
}

Publication Information:

Received 19 January 2021, Accepted 23 May 2021, Available online 29 June 2021

DOI: $10.21463 /$ jmic.2021.10.1.10

\section{Abstract}

Islands have ecological value and play roles such as maritime boundaries and territorial protection, but their economic outlook is not bright, and above all, improving residential conditions is difficult due to their aging and declining populations. Education on islands is worse than some of their other underdeveloped sectors. Therefore, this study investigated the current status of education and improvement plans for the island of Ulleungdo, South Korea. According to a survey of 327 of its residents, school education played an important role in finding employment, and the most frequent response was that the number of experts in charge of education on Ulleungdo was insufficient. The measures suggested for improving lifelong education were developing and distributing programs and strengthening the professionalism of educators.

To solve the educational problems on Ulleungdo, we suggest the following: develop educational programs for parents, offer career experiences for youths and young adults, establish Ulleung County People's University, and support learning clubs.

\section{Keywords}

island, Ulleungdo, education, lifelong education

\section{Introduction}

Most South Koreans (hereafter, Koreans) view islands positively. According to the KMI Weekly Report (2019), approximately $80 \%$ of Koreans perceive an island as a beautiful, clear, pleasant, and leisurely place. The islands of 
Ulleungdo and Dokdo have been recognized as the most well-preserved islands, due to their clean image and safeguard maritime boundaries and territories. Support for this perception includes Koreans' willingness to pay additional taxes for policies to manage and preserve the islands (Park et al., 2019). Thus, for Koreans, these islands are worth preserving and play an important role in establishing maritime sovereignty.

Unlike the island's various values and heightened public awareness, the economic outlook is not promising. In the local economy, population reductions and aging are likely to cause a rapid decrease in the productive population, adversely affecting the overall economic situation (Bloom and Williamson, 1998). The aging index for islands was 154.9 in 2016, approximately 1.5 times higher than South Korea's average of 101.1 in 2016 and 1.3 times higher from 120.4 in 2010 to 154.9 in 2016; the population of islands in South Korea was approximately 880,000 in 2016, accounting for $1.64 \%$ of its total population $(\mathrm{KMl}, 2018)$. If this phenomenon continues, uninhabited islands will be unable to fully realize their tourism and marine resources.

To solve this problem, the South Korean government is devising a comprehensive island development policy to improve the settlement conditions of the islands, so that residents can continue to reside there. However, the island is vulnerable to infrastructure because it is separated from the land; thus, it is vulnerable to, for example, traffic, roads, education, medical care (Park and Lee, 2019). The weak settlement conditions in underdeveloped areas are a factor that can increase population outflow and aging, hindering the local economy (Ahn et al., 2016). Despite the South Korean government's policy, the island is poor compared with other underdeveloped areas in the country due to poor access to the mainland, outdated public transportation, and the lack of educational services (Park, 2016). Among them, education is a difficult task to find, even though it has long been raised along with other rural areas.

Studies have suggested measures to improve the poor educational environment on the islands of South Korea (Ki, 2004; Suh and Lee, 2020). The education status of South Korea's islands and rural areas was investigated, and the institutional improvement measures or policy directions were assessed (Park and Lee, 2019). The literature also discussed the educational gap between South Korea's islands and urban areas, and between urban and rural areas, and means to resolve it ( $\mathrm{Na}$ et al., 2007).

Ulleungdo is a relatively poor island compared with the educational environment in urban areas, resulting in a decrease in the number of students and schools, a lack of professional manpower, a lack of choice in educational programs, and an educational gap. In particular, due to the educational gap, students residing on islands have moved to large cities in their middle and high school years to attain a better education, which is widening the educational gap between the islands and the cities. The education facilities on the island have quantitatively increased through the enactment of the "Island and Remote Area Education Promotion Act" established by the Ministry of Education Ordinance, but the absence of human resources such as education experts has not been resolved. To improve educational problems on the islands, research is being conducted on the educational environment, the educational status, policy improvement measures, and the educational gap.

However, research on the problems, effects, and programs of school education on islands has not been investigated. In particular, research on Ulleungdo has mainly focused on the natural and scientific fields; thus, few studies have been conducted in the humanities and social sciences. Hwang Kyung-hee (2014) mentioned the current state of the curriculum and educational facilities while analyzing the characteristics of Ulleungdo students' entrance into school. Therefore, due to the lack of research, it is necessary to discuss Ulleungdo's education issues. 


\section{Research Site and Analysis Method}

Ulleungdo is the largest island east of South Korea and a member of the only island group in the East Sea. Traveling to and from the eastern coast of the Korean Peninsula is difficult because the trip is on average approximately $180 \mathrm{~km}$. According to the Korean Statistical Information Service, as of 2019, the total population of Ulleungdo was 9,617, of which 6,766 , approximately $70 \%$, reside in Ulleung-eup, a county on the island. Ulleungdo's population has decreased from 10,701 in 2010 to less than 10,000 since 2017, and the average annual population growth rate has continued to decline over the past decade. The island's population structure is as follows: $7.6 \%$ of the nonproductive population is aged 15 years or younger, $68.3 \%$ of the productive population, and $24.3 \%$ are aged 65 or older. Thus, Ulleungdo is a super-aged society, and urgent responses to this phenomenon are necessary. The net outflow of the population is also a problem. Except for 2017, the net outflow has been approximately 137 people annually since 2012 .

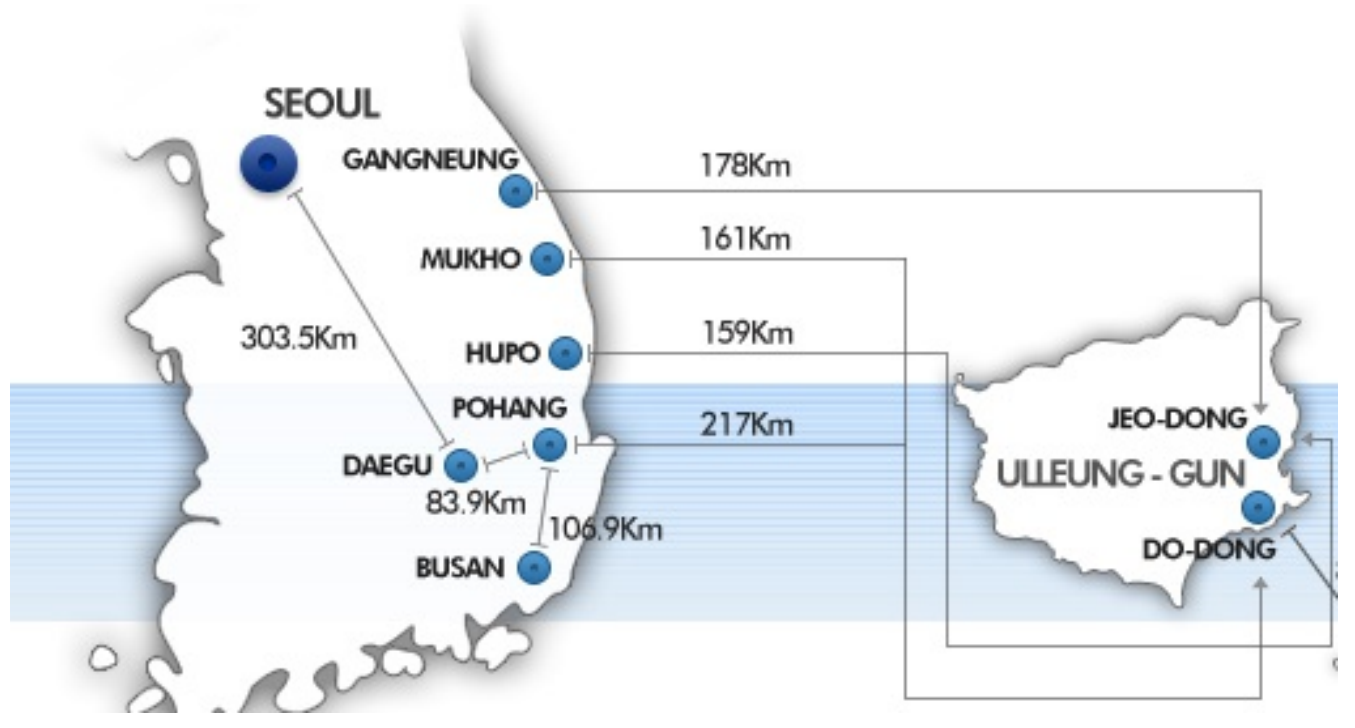

Fig 1. Map of study area

Poor settlement conditions can be cited as the reason for the population problems. According to statistics from the local government of Ulleung-gun, the housing supply rate is approximately $70 \%$, which is lower than the $104.2 \%$ for all of South Korea. Moreover, most of the houses are aged older than 30 years; thus, some properties are in unsafe conditions. Social welfare facilities, such as children's welfare facilities and leisure facilities for elderly individuals, are minimal, and no medical facilities with expertise such as general hospitals are available; thus, residents must travel to the mainland for medical treatment. In terms of educational conditions, the island has five elementary schools, four middle schools, and one specialized high school. Because there are no general high schools and universities, Ulleungdo students must leave Ulleungdo to receive a general education.

The data used in this paper are the results of a survey conducted by Ulleung-gun and the Daegu-Gyeongbuk Development Institute: the "Ullung-gun Residents Consciousness Survey." The questionnaire was structured for the residents of Ulleungdo. Although this questionnaire was designed for a fact-finding analysis of overall residential conditions, it was analyzed after extracting parts related to education. 
Table 1. General characteristics of the sample

\begin{tabular}{|c|c|c|c|}
\hline & & Sample & $\%$ \\
\hline & Total & 327 & $100.0 \%$ \\
\hline \multirow{2}{*}{ Gender } & Male & 177 & $54.1 \%$ \\
\hline & Female & 150 & $45.9 \%$ \\
\hline \multirow{6}{*}{ Ages } & $20 \mathrm{~s}$ & 40 & $12.2 \%$ \\
\hline & $30 \mathrm{~s}$ & 70 & $21.4 \%$ \\
\hline & $40 \mathrm{~s}$ & 57 & $17.4 \%$ \\
\hline & $50 \mathrm{~s}$ & 63 & $19.3 \%$ \\
\hline & $60 \mathrm{~s}$ & 51 & $15.6 \%$ \\
\hline & 70 and over & 46 & $14.1 \%$ \\
\hline \multirow{7}{*}{ Length of residence } & Less than 5 years & 76 & $23.2 \%$ \\
\hline & 5 years under 10 years & 34 & $10.4 \%$ \\
\hline & 10 years under 15 years & 16 & $4.9 \%$ \\
\hline & 15 years under 20 years & 19 & $5.8 \%$ \\
\hline & 20 years under 25 years & 33 & $10.1 \%$ \\
\hline & 25 years under 30 years & 24 & $7.3 \%$ \\
\hline & Over 30 years & 125 & $38.2 \%$ \\
\hline \multirow{10}{*}{ Occupational cluster } & Primary industry & 30 & $9.2 \%$ \\
\hline & Tourism & 29 & $8.9 \%$ \\
\hline & Self-employed people except for tourism & 46 & $14.1 \%$ \\
\hline & Office workers & 38 & $11.6 \%$ \\
\hline & Specialized job & 23 & $7.0 \%$ \\
\hline & Students & 7 & $2.1 \%$ \\
\hline & Housewife & 25 & $7.6 \%$ \\
\hline & Public official & 92 & $28.1 \%$ \\
\hline & Inoccupation & 29 & $8.9 \%$ \\
\hline & Others & 8 & $2.4 \%$ \\
\hline
\end{tabular}

The survey was conducted from March to April 2020. The sample size was 327 residents. One-on-one direct interviews were also conducted. The general characteristics of the sample are shown in Table 1. The population was $54.1 \%$ men and $45.9 \%$ women. The age distribution of the respondents in years was $12.2 \%$ in their $20 \mathrm{~s}, 21.4 \%$ in their $30 \mathrm{~s}, 17.4 \%$ in their $40 \mathrm{~s}, 19.3 \%$ in their $50 \mathrm{~s}, 15.6 \%$ in their $60 \mathrm{~s}$, and $14.1 \%$ aged 70 and older. The greatest number of respondents worked in public institutions (28.1\%), followed by self-employed except for tourism (14.1\%), office workers (11.6\%), primary industry workers (9.2\%), and tourism-related workers ( $8.9 \%$ ); for the duration of residence, $38.2 \%$ had resided on the island for more than 30 years; $23.2 \%$, less than 5 years; and $10.4 \%, 5$ to 10 years. This can be inferred from the recent, rapid rise of Ulleungdo as a tourist destination, which has led to an increase in the number of migrants.

This study used SPSS 20.0 to analyze the data. The specific analysis methods of this study are as follows: First, frequency analysis was conducted to examine the demographic and sociological characteristics of the surveyed sample. 
Second, independent sample t verification and one-way distribution analysis were conducted to analyze the educational conditions, educational effects, and after-school class satisfaction

\section{Results}

\section{Effect Analysis of School Education}

The effect of school education was investigated to assess how the residents of Ulleungdo perceived it. The main variables were moral education, employment, knowledge and skill acquisition, and social view establishment, and the responses were on a five-point scale.

An independent sample $t$ test was conducted to verify that significant differences in key variables were observed by gender. As a result, employment varies significantly by gender $(t=-2.014, p<.05)$, and men $(M=2.67)$ had a lower employment rate than women $(M=2.93)$. By contrast, moral education, knowledge and skill acquisition, and social view establishment showed no significant differences by gender.

Table 2. Recognition of the effects of school education by gender

\begin{tabular}{|c|c|c|c|c|c|c|}
\hline Subordination variable & Group & Samples & M & SD & $\mathrm{t}$ & $\mathrm{p}$ \\
\hline \multirow[t]{2}{*}{ Moral education } & Male & 131 & 3.02 & 0.80 & \multirow[t]{2}{*}{-0.670} & \multirow[t]{2}{*}{0.503} \\
\hline & Female & 118 & 3.09 & 0.86 & & \\
\hline \multirow[t]{2}{*}{ Employment } & Male & 131 & 2.67 & 0.96 & \multirow[t]{2}{*}{$-2.014^{\star}$} & \multirow[t]{2}{*}{0.045} \\
\hline & Female & 118 & 2.93 & 1.08 & & \\
\hline \multirow[t]{2}{*}{ Knowledge and skill acquisition } & Male & 131 & 2.90 & 0.86 & \multirow[t]{2}{*}{-0.849} & \multirow[t]{2}{*}{0.397} \\
\hline & Female & 118 & 3.00 & 0.99 & & \\
\hline \multirow[t]{2}{*}{ Social view establishment } & Male & 131 & 2.93 & 0.81 & \multirow[t]{2}{*}{-1.431} & \multirow[t]{2}{*}{0.154} \\
\hline & Female & 118 & 3.09 & 0.98 & & \\
\hline
\end{tabular}

A one-way analysis of variance was conducted to verify that the means of key variables significantly differed by age and duration of residence. As a result, employment by age group $(F=3.471, p<.05)$, knowledge and skill acquisition $(F=$ $3.165, p<.05)$, and social view establishment $(F=3.711, p<.05)$ showed significant differences. By contrast, moral education had no significant differences among age groups. In addition, for knowledge and skill acquisition, only $(F=$ $3.641, p<.05)$ significant differences were found. Scheffe post analysis was performed on variables that had significant differences. The results demonstrated that respondents aged in their $60 \mathrm{~s}$ and older were higher than those aged in their 30 s or younger for employment, knowledge and skill acquisition, and social view establishment. 
Table 3. Recognition of the effects of school education by age and length of residence

\begin{tabular}{|c|c|c|c|c|c|c|c|c|}
\hline Subordination variable & \multicolumn{2}{|c|}{ Group } & Samples & M & SD & f & $\mathrm{p}$ & Scheffe \\
\hline \multirow[t]{6}{*}{ Employment } & \multirow[t]{3}{*}{ Age } & Under 30s & 68 & 2.62 & 1.01 & \multirow[t]{3}{*}{$3.471^{*}$} & \multirow[t]{3}{*}{0.033} & \multirow[t]{3}{*}{ Under 30 s $<$ over 60 s } \\
\hline & & $40 \mathrm{~s} \sim 50 \mathrm{~s}$ & 104 & 2.73 & 1.01 & & & \\
\hline & & Over 60s & 77 & 3.04 & 1.03 & & & \\
\hline & \multirow[t]{3}{*}{ Length of residence } & Under 10 years & 70 & 2.71 & 0.93 & \multirow[t]{3}{*}{2.155} & \multirow[t]{3}{*}{0.118} & \multirow[t]{3}{*}{-} \\
\hline & & 10 20 years & 30 & 2.50 & 0.97 & & & \\
\hline & & Over 20 years & 149 & 2.89 & 1.07 & & & \\
\hline \multirow[t]{6}{*}{ Knowledge and skill acquisition } & \multirow[t]{3}{*}{ Age } & Under 30s & 68 & 2.72 & 0.88 & \multirow[t]{3}{*}{$3.165^{\star}$} & \multirow[t]{3}{*}{0.044} & \multirow[t]{3}{*}{ Under 30 s $<$ over 60 s } \\
\hline & & $40 \mathrm{~s} \sim 50 \mathrm{~s}$ & 104 & 2.99 & 0.92 & & & \\
\hline & & Over 60s & 77 & 3.09 & 0.93 & & & \\
\hline & \multirow[t]{3}{*}{ Length of residence } & Under 10 years & 70 & 2.79 & 0.90 & \multirow[t]{3}{*}{$3.641^{\star}$} & \multirow[t]{3}{*}{0.028} & \multirow[t]{3}{*}{ Same } \\
\hline & & 10 20 years & 30 & 2.70 & 0.84 & & & \\
\hline & & Over 20 years & 149 & 3.07 & 0.93 & & & \\
\hline \multirow[t]{6}{*}{ Social view establishment } & \multirow[t]{3}{*}{ Age } & Under 30s & 68 & 2.79 & 0.86 & \multirow[t]{3}{*}{$3.711^{*}$} & \multirow[t]{3}{*}{0.026} & \multirow[t]{3}{*}{ Under 30 s < over 60 s } \\
\hline & & $40 s \sim 50 s$ & 104 & 3.01 & 0.91 & & & \\
\hline & & Over 60s & 77 & 3.19 & 0.87 & & & \\
\hline & \multirow[t]{3}{*}{ Length of residence } & Under 10 years & 70 & 2.84 & 0.93 & \multirow[t]{3}{*}{3.004} & \multirow[t]{3}{*}{0.051} & \multirow[t]{3}{*}{-} \\
\hline & & 10 20 years & 30 & 2.83 & 0.99 & & & \\
\hline & & Over 20 years & 149 & 3.12 & 0.85 & & & \\
\hline
\end{tabular}

\section{Education Problems on Ulleungdo}

On Ulleungdo, residents' perception of the effect of school education differed by age. Therefore, the analysis of the public education problems on Ulleungdo was conducted by age. Frequency analysis and cross-analysis were conducted to assess the reported educational problems on Ulleungdo. The cross-analysis included gender, age group, and residence period as the independent variables, with only significant differences between age groups. Among the education problems, the top three responses were as follows: an insufficient number of professionals to teach students (83 respondents, $26.5 \%$ ), no environment to develop creative talent (49 respondents, $15.7 \%$ ), and no regular high schools (44 respondents, $14.1 \%$ ).

Cross tabulation was derived to verify the difference in the proportion of the perception of education problems by age. The results demonstrated that of all respondents, those aged in their 20s reported the greatest shortage of arts and physical education (23.1\%); those aged in their $30 \mathrm{~s}, 40 \mathrm{~s}, 60 \mathrm{~s}$, and 70 and over reported the greatest shortage of professionals who could provide education; and those in their 50 s were the most absent from regular high schools (26.2\%). 


\section{Necessary Measures to Improve the Environment of Lifelong Education on Ulleungdo}

In addition, lifelong education has been recently highlighted in adult education. Lifelong education is a concept that encompasses school and social education, and today, most countries are redefining their educational system on the basis of this concept (Fisher, Gerhard, 2000). The diversity and quality of lifelong education have substantially affected adult education welfare, but regional differences have been observed.

Table 4. Cross-analysis of educational problems by age

\begin{tabular}{|l|l|l|l|l|l|l|l|}
\hline & \multicolumn{1}{|c|}{$20 \mathrm{~s}$} & \multicolumn{1}{|c|}{$30 \mathrm{~s}$} & \multicolumn{1}{|c|}{$40 \mathrm{~s}$} & \multicolumn{1}{|c|}{$50 \mathrm{~s}$} & \multicolumn{1}{|c|}{$60 \mathrm{~s}$} & \multicolumn{1}{|c|}{70 and over } & \multicolumn{1}{|c|}{ Total } \\
\hline Deterioration of public education facilities & $5(12.8)$ & $8(11.8)$ & $8(14.0)$ & $4(6.6)$ & $3(6.7)$ & $1(2.3)$ & $29(9.3)$ \\
\hline Absence of general high school & $4(10.3)$ & $6(8.8)$ & $5(8.8)$ & $16(26.2)$ & $11(24.4)$ & $2(4.7)$ & $44(14.1)$ \\
\hline Environmental degradation of private education & $6(15.4)$ & $9(13.2)$ & $10(17.5)$ & $7(11.5)$ & $2(4.4)$ & $7(16.3)$ & $41(13.1)$ \\
\hline Lack of creative talent development environment & $3(7.7)$ & $11(16.2)$ & $11(19.3)$ & $11(18.0)$ & $6(13.3)$ & $7(16.3)$ & $49(15.7)$ \\
\hline Insufficient arts and physical education & $9(23.1)$ & $7(10.3)$ & $3(5.3)$ & $4(6.6)$ & $3(6.7)$ & $5(11.6)$ & $31(9.9)$ \\
\hline Lack of lifelong education & $4(10.3)$ & $3(4.4)$ & $4(7.0)$ & $6(9.8)$ & $5(11.1)$ & $2(4.7)$ & $24(7.7)$ \\
\hline Lack of professional training personnel & $6(15.4)$ & $20(29.4)$ & $15(26.3)$ & $13(21.3)$ & $12(26.7)$ & $17(39.5)$ & $83(26.5)$ \\
\hline Others & $2(5.1)$ & $4(5.9)$ & $1(1.8)$ & $0(0.0)$ & $3(6.7)$ & $2(4.7)$ & $12(3.8)$ \\
\hline Total & $39(100.0)$ & $68(100.0)$ & $57(100.0)$ & $61(100.0)$ & $45(100.0)$ & $43(100.0)$ & $313(100.0)$ \\
\hline
\end{tabular}

x2: $49.982, p<.05 /$ unit: frequency $(\%)$

Frequency analysis and cross-analysis were conducted to assess what policies are necessary to improve the lifelong educational environment for the residents of Ulleungdo. The cross-analysis included gender, age group, and residence period as independent variables, with only significant differences between age groups.

We found that the measures reported to be the most necessary to improve the lifelong educational environment on the island were the development and dissemination of various lifelong education programs (146 respondents, $45.8 \%$ ), the establishment of lifelong education centers (50 respondents, $15.7 \%$ ), and the strengthening of educators' expertise (40 respondents, $12.5 \%)$.

The results of cross-analysis based on age also demonstrated that the greatest number of responses were in favor of program development and dissemination. However, the next most frequently answered factors had differences: respondents aged in their $30 \mathrm{~s}$ and 40 s cited strengthening the professionalism of educators, and the remaining age group reported establishing a lifelong education center. 
Table 5. Cross-analysis by age of the improvement of lifelong education

\begin{tabular}{|l|l|l|l|l|l|l|l|}
\hline & \multicolumn{1}{|c|}{$20 \mathrm{~s}$} & \multicolumn{1}{|c|}{$30 \mathrm{~s}$} & \multicolumn{1}{|c|}{$40 \mathrm{~s}$} & \multicolumn{1}{|c|}{$50 \mathrm{~s}$} & \multicolumn{1}{|c|}{ Tos } & \multicolumn{1}{|c|}{ Over 70 } & \multicolumn{1}{c|}{ Total } \\
\hline Program dissemination & $15(38.5)$ & $30(44.8)$ & $30(53.6)$ & $28(44.4)$ & $21(42.9)$ & $22(48.9)$ & $146(45.8)$ \\
\hline Establishment of lifelong education center & $6(15.4)$ & $11(16.4)$ & $8(14.3)$ & $10(15.9)$ & $7(14.3)$ & $8(17.8)$ & $50(15.7)$ \\
\hline Establishment of higher education institution & $4(10.3)$ & $5(7.5)$ & $2(3.6)$ & $4(6.3)$ & $6(12.2)$ & $1(2.2)$ & $22(6.9)$ \\
\hline Promotion of lifelong education & $7(17.9)$ & $2(3.0)$ & $2(3.6)$ & $8(12.7)$ & $4(8.2)$ & $6(13.3)$ & $29(9.1)$ \\
\hline Reinforcement of educator expertise & $3(7.7)$ & $13(19.4)$ & $11(19.6)$ & $8(12.7)$ & $3(6.1)$ & $2(4.4)$ & $40(12.5)$ \\
\hline Raise local government interest & $1(2.6)$ & $2(3.0)$ & $1(1.8)$ & $1(1.6)$ & $3(6.1)$ & $4(8.9)$ & $12(3.8)$ \\
\hline Tuition support & $3(7.7)$ & $2(3.0)$ & $1(1.8)$ & $0(0.0)$ & $2(4.1)$ & $0(0.0)$ & $8(2.5)$ \\
\hline Open educational facilities & $0(0.0)$ & $2(3.0)$ & $1(1.8)$ & $4(6.3)$ & $3(6.1)$ & $0(0.0)$ & $10(3.1)$ \\
\hline Others & $0(0.0)$ & $0(0.0)$ & $0(0.0)$ & $0(0.0)$ & $0(0.0)$ & $2(4.4)$ & $2(0.6)$ \\
\hline Total & $39(100.0)$ & $67(100.0)$ & $56(100.0)$ & $63(100.0)$ & $49(100.0)$ & $45(100.0)$ & $319(100.0)$ \\
\hline
\end{tabular}

$x 2: 57.716, p<.05 /$ unit: frequency $(\%)$

\section{Conclusion and Implications}

The purpose of this study was to identify educational problems on the island of Ulleungdo on the basis of its residents' responses and propose improvement measures. To achieve this objective, a survey was conducted among the island's residents to elicit their perceptions of the island's current status of education and to analyze the data by gender and age. The main results of this study are summarized as follows:

First, we analyzed whether the residents of Ulleungdo perceived that the island's school education was effective in helping students achieve the following outcomes: find employment, acquire knowledge and skills, and establish a social outlook. In particular, women's perception of "employment" was higher than that of men because women were in charge of educating their children. It was also recognized that the greater the age, the greater the effect of school education. This is consistent with the research that has demonstrated that perceptions and roles of public education change with the times (Hur, 2019).

Second, the problem reported most frequently, among the educational issues of Ulleungdo, was the insufficient number of professional personnel to provide education. These results support those of studies that have demonstrated South Korean teachers' avoidance of work in elementary schools on islands and rural areas, which is emerging as serious problems in the nation's education system (Hwang and Park, 2018). The geographical environment of teachers working on islands and in rural areas has prevented them from fully realizing their professional development opportunities, and there are no applicants due to the authoritative, outdated school culture, uncomfortable relationships with faculty members and residents, and heavy load of school work (Park and Park, 2018; Hwang, 2019). Therefore, to secure that teachers will work on Ulleungdo, the government should legislate a mandatory service system for islands and rural areas, and the appropriate social, psychological, cultural, and educational environment should be promoted to provide acceptable conditions for teachers. 
Third, the respondents perceived a considerable lack of lifelong education programs and that the development and dissemination of lifelong education programs were necessary. Adult lifelong education programs are operated by lifelong education institutions, public libraries, and cultural facilities, but the facilities on Ulleungdo are unequipped to operate lifelong education programs, due to the regional characteristics. According to the Korea Educational Development Institute (2019), there were 141,351 programs for adults among all lifelong education programs, accounting for approximately $75.1 \%$ of the total programs, up from 18,461 or $15 \%$ from the previous year. In other words, many lifelong education programs are available to adults in South Korea, but Ulleungdo is not providing programs due to the insufficiently equipped facilities and the insufficient number of professionals. In addition, Kim and Kim (2019) demonstrated that in South Korea, lifelong education programs on islands or in rural areas have a positive impact on life satisfaction. Therefore, lifelong education for adults on Ulleungdo is essential, and policy support is necessary to provide it (Kim and Kim, 2019).

The results of this study suggest that to support lifelong adult education, the following practical, policy alternatives are suggested:

First, develop educational programs in which parents and children can participate together. The public library can be used to develop various content such as that of culture and arts, ecology, safety, and nutrition. This suggestion can help children develop healthy growth and form a family community.

Second, career experience exploration activities for teenagers and young people should be supported. Ulleungdo has many jobs related to the agricultural and fisheries industries and tourism industries but relatively few employment opportunities in other areas. Due to this environment, teenagers have a narrow choice of careers. Therefore, the local government should support teenagers and young adults to choose their career paths by exploring inland jobs on their vacations.

Third, establishing Ulleung County People's University is necessary. Ulleungdo has no higher education institution due to its geographical limitations. Online universities such as Korea Communications University and Cyber University are also restricted from offline gatherings, tests, and library use. To improve this poor level of educational welfare, adult participation in higher education must be expanded. Local human resources promoted through this initiative would affect regional development.

Finally, encouraging learning activities is essential to fostering self-directed lifelong learners by supporting autonomous learning organizations. Local governments should financially support certain activity costs of these organizations to promote growth. However, due to limited budgets, a better policy would be to develop programs by using existing public libraries than establishing a lifelong education center.

\section{References}

Ahn, S.-J., Kim, J.-P., Ryu, Y.-S., Kim, K.-C., 2016. The influence of residence condition on the residence satisfaction in the less developed areas - in the case of invigorating areas in Gyeongsangbuk-do. J Korea Regional Economics: 67-86.

Bloom, D.E., Williamson, J.G., 1998. Demographic transitions and economic miracles in emerging Asia. World Bank Econ. Rev., $12: 419-455$.

Fischer, G., 2000. Lifelong learning - more than training. J. Interact. Learn. Res., 11: 265-294.

Hur, C.S., 2019. Inquiring the possibility of critical pedagogy as discourse for 'zeitgeist'. J. Korea Contents Assoc., 19: 80-91. 
Hwang, K.-H., 2014. Effects of academic age and family relationships on entering school in island area-Focus on Ulleung Island, M.A. thesis, Yeungnam University.

Hwang, Y.H., 2019. Kentucky educational reform implications for the education of remote and rural schools: focusing on Jeollanamdo Provincial Education. Korean Educ. Inq. 37: 87-113.

Hwang, Y.H., Park, N.G., 2018. An exploratory study on attainments, limitations, and alternatives for GNUE's admission system by recommendation of the chief superintendent of the provincial office of education. J. Korean Educ., 45: 165-191.

Ki, J.S., Jung, H.W., 2006. A study on students' academic achievement satisfaction of Korean island regions. Educ. Res., 18: 1-10.

Ki, J.S., 2001. A study on the relation between educational environment and educational result in Islands Area. Educ. Res., 14: $139-151$.

Kim, H.J., Kim, J.T., 2019. An analysis on the regional differences of improvement in quality of life among participants in lifelong learning. Korean Local Admin. Rev., 13: 121-147.

KMI, 2018. Kim weekly report. 87: 1-9.

KMI, 2019. KIM weekly report. 128: 1-14.

Na, S.I., Jyong, C.Y., Gu, J.O., Park, H.M., Chang, H.S., Kim, J.G., Ma, S.J., Jo, D.B., Moon, S.Y., 2007. Exploring action plan for the education innovation by types of rural areas for releasing education gaps between urban and rural areas. Korean Society by Agricultural Education and Humen Resource Development, 39: 35-57.

Park, N.G., Park, H.W., 2018. Perceptions of pre-service elementary school teachers on teacher sorting mitigation methods. J. Korean Teach Educ. 35: 1-27.

Park, S.H., Lee, T.G., 2019. The status and improvement of Korea Island Education in institutions - A Case Study of Jeollanam-do Province -. J. Korean Isl., 31: 109-129.

Park, S.-H., 2016. A strategic approach to policy tasks for the development of Korea's island areas. J. Mar. Island Cult. 5: 14-21.

Park, S.-H., Choi, J.-H., Lee, G.-A., 2019. A study on evaluation of non-market value of islands with fewer. J. Mar. Island Cult., 8: $103-112$.

Park, S.-H., Lee, G.-A., 2019. Policy suggestions to improve living conditions of small islands with fewer than 10 residents. J. Mar. Island Cult, 8 : 48-60.

Suh, Y.W., Lee, C.M., 2020. A study on the improvement of the educational environment of the youth on islands - Centered on Educational Support Organization (Tentative Name). J. Korean Isl. 32: 27-48. 